\title{
High IGF2 expression is associated with poor clinical outcome in human ovarian cancer
}

\author{
YAN DONG ${ }^{1,2},{\text { JIANJUN } \mathrm{LI}^{3}, \text { FEI HAN }}^{1,2}$, HONGQIANG CHEN $^{1,2}$, XIAOXIN ZHAO $^{3}$, \\ QIN QIN $^{3}$, RONGHUI SHI ${ }^{1,2}$ and JINYI LIU ${ }^{1,2}$ \\ ${ }^{1}$ Institute of Toxicology, College of Preventive Medicine, Third Military Medical University; ${ }^{2}$ Key Laboratory \\ of Medical Protection for Electromagnetic Radiation, Ministry of Education of China; ${ }^{3}$ Department of \\ Oncology, Southwest Hospital, Third Military Medical University, Chongqing, P.R. China
}

Received March 20, 2015; Accepted May 6, 2015

DOI: $10.3892 /$ or.2015.4048

\begin{abstract}
Ovarian cancer is one of the most common types of cancer in females and is the leading cause of death among gynaecological cancers in women worldwide. In the present study, we identified insulin-like growth factor 2 (IGF2) as a differentially expressed gene between cancerous and noncancerous ovarian tissues. IGF2 was frequently increased in the human ovarian cancers when compared to the frequency in the non-cancerous ovarian tissues both at the mRNA (30/35) and protein level (61/72). The mean level of IGF2 in the tumor tissues was markedly higher than that in the non-cancerous tissues (nearly 3 -fold change) $(\mathrm{P}=0.000)$. There was a significant correlation of IGF2 expression with histological grade $(\mathrm{P}=0.047)$. Kaplan-Meier analysis indicated that the ovarian cancer patients with high IGF2 expression showed a poorer prognosis both in regards to overall survival (OS) and progression-free survival (PFS) $(\mathrm{n}=1,648, \mathrm{P}=0.000)$. Further analysis revealed that high expression of IGF2 was an unfavorable factor for the prognosis of the ovarian cancer patients at clinical stage I + II, stage III, histological grade 2, grade 3 or those treated with chemotherapy containing platin and Taxol. Our data provide evidence that IGF2 expression is frequently increased in ovarian cancer tissues, and high expression of IGF2 may be a significant prognostic factor for poor survival in ovarian cancer patients.
\end{abstract}

\section{Introduction}

Ovarian cancer is one of the most common and lethal gynecologic cancer in women worldwide, and the incidence of this cancer has been increasing in many countries (1-3). More than 200,000 new cases of ovarian cancer were diagnosed in 2011

Correspondence to: Professor Jinyi Liu, Institute of Toxicology, College of Preventive Medicine, Third Military Medical University, 30 Gaotanyan Street, Shapingba, Chongqing 400038, P.R. China E-mail: jinyiliutmmu@163.com

Key words: IGF2 expression, overall survival, prognostic factor, ovarian cancer worldwide (4). At present, most ovarian cancer patients are diagnosed at an advanced stage due to the lack of effective detection at early stages (5). Although advances in surgery and chemotherapy have been developed, only $\sim 30 \%$ of patients achieve a 5-year survival after diagnosis (6). To date, surgery is still of importance for improving the effect of chemotherapy and the survival rate. Chemotherapy is an important strategy and the combination of platinum and taxane has been used as the reference standard for the chemotherapy of ovarian cancer (7). This standard combination shows effectiveness with a response rate of $\sim 80 \%$ in advanced ovarian cancer patients, while unfortunately most of these patients relapse owing to drug resistance $(8,9)$. Therefore, identification of molecular biomarkers with clinicopathologic and prognostic significance is critically important for improving therapeutic methods and prolonging the survival of ovarian cancer patients.

Insulin-like growth factor 2 (IGF2) is a mitogenic peptide hormone, which is expressed in most tissues (10). Serum IGF2 is usually low in newborns, increasing in childhood and remaining at a similar concentration in adults, although it may decrease slightly in healthy elders $(11,12)$. Many studies have shown that IGF2 regulates cell growth, differentiation and metabolism (13). Particularly, it is highly expressed during embryogenesis, and is important in promoting fetal growth (14). Growing evidence has shown that IGF2 can promote cancer development and progression (15). In hepatocellular carcinoma, the expression of IGF2 is usually elevated in patients (16). In esophageal cancer, high IGF2 expression is associated with reduced disease-free survival (17). The differential expression of IGF2 between African-American and Caucasian patients is believed to contribute to breast cancer survival disparities (18). However, the clinical significance of IGF2 expression remains unclear in ovarian cancer.

In the present study, we also identified IGF2 as a differentially expressed gene between tumor and non-tumor ovarian tissues (19), and we confirmed its expression in normal, corresponding non-cancerous and cancerous ovarian tissues by reverse transcription-polymerase chain reaction (RT-PCR), real-time quantitative PCR (RT-qPCR), western blotting and IHC. Furthermore, the prognostic significance of IGF2 expression was analyzed in human ovarian cancers. Our study showed that IGF2 expression is frequently higher in ovarian 
cancer tissues, and the expression pattern may be an important prognostic factor for ovarian cancer patients.

\section{Materials and methods}

Patient samples. A total of 72 tumor, 15 para-carcinoma and 10 normal ovarian tissues were obtained from the Southwest Hospital in Chongqing, China. The present study was approved by the Ethics Committee of the Southwest Hospital in Chongqing, China. Informed consent was signed by all of the recruited patients.

Isolation of total RNA. Total RNAs were extracted from frozen tissues. Approximately $2.0 \mu \mathrm{g}$ of total RNAs was treated with DNase I to eliminate the genomic DNA contamination, and then were reverse-transcribed to generate cDNAs.

Analysis of IGF2 expression by RT-PCR and RT-qPCR. IGF2 expression was determined by RT-PCR. A series of PCRs with different cycles was performed. Based on the pilot experiments, the appropriate cycles were chosen. Human $\beta$-actin was amplified as an endogenous control. The primers for IGF2 and $\beta$-actin were (5'-3'): IGF2-F, TAC TTC AGC AGG CCC GCA AG and IGF2-R, GGT GAC GTT TGG CCT CCC TG; $\beta$-actin-F, TTC TAC AAT GAG CTGCGT GTG and $\beta$-actin-R, GGG GTG TTG AAG GTC TCA AA. RT-qPCR was performed using an iQ5 Real-Time Detection system (Bio-Rad Laboratories, Hercules, CA, USA) and GoTaq ${ }^{\circledR}$ qPCR Master Mix (Promega). The relative gene expression was calculated by the equation $2^{-\Delta \Delta C T}$. The sequences of the primers were (5'-3'): IGF2-F1, GAT GCT GGT GCT TCT CAC CT and IGF2-R1, CAG ACG AAC TGG AGG GTG TC; $\beta$-actin-F2, TGA CGT GGA CAT CCG CAA AG and $\beta$-actin-R2, CTG GAA GGT GGA CAG CGA GG. All RT-qPCRs were performed in triplicate.

Tissue microarray generation. To construct the tissue microarray (TMA) slides, two cores were obtained from each representative tumor and adjacent non-cancerous tissue (within a distance of $20 \mathrm{~mm}$ ). The non-cancerous adjacent tissues were stained with hematoxylin and eosin, and then reviewed histologically by two pathologists, and compared with normal tissue. Duplicate cylinders from intratumoral and peritumoral areas were obtained, and the TMA containing 72 tumor and 15 peritumoral ovarian tissues was constructed (20).

Western blot analysis. Western blotting (WB) was performed using the IGF2 antibody (Santa Cruz Biotechnology) as previously described (21). Protein $(100 \mu \mathrm{g})$ was run on $8 \%$ SDS-PAGE and transferred to PVDF membranes (Millipore). The membranes were blocked and incubated with the primary antibody (IGF2, 1:1,000; Santa Cruz Biotechnology). Then, the membranes were washed, incubated with the secondary antibody (1:3,000; Jackson ImmunoResearch Laboratories), and developed with SuperSignal West Pico chemiluminescent substrate (Pierce). The same membrane was stripped and incubated with $\beta$-actin (Sigma) serving as an internal control.

Immunohistochemical analysis. Immunohistochemistry was performed using the IGF2 antibody (1:50; Santa Cruz
Table I. Correlations of IGF2 expression with clinicopathologic features of the ovarian cancer patients $(n=72)$.

\begin{tabular}{|c|c|c|c|c|}
\hline \multirow[b]{2}{*}{ Clinical feature } & \multirow[b]{2}{*}{ Total } & \multicolumn{2}{|c|}{ IGF2 expression } & \multirow[b]{2}{*}{ P-value } \\
\hline & & $\begin{array}{l}\text { High } \\
(n=41)\end{array}$ & $\begin{array}{c}\text { Low } \\
(n=31)\end{array}$ & \\
\hline \multicolumn{5}{|l|}{ Age (years) } \\
\hline$<55$ & 40 & 22 & 18 & \multirow[t]{2}{*}{1.000} \\
\hline$\geq 55$ & 28 & 16 & 12 & \\
\hline \multicolumn{5}{|l|}{ Histological type } \\
\hline Serous & 39 & 22 & 17 & \multirow[t]{2}{*}{1.000} \\
\hline Other & 33 & 19 & 14 & \\
\hline \multicolumn{5}{|c|}{ Histological grade } \\
\hline $1+2$ & 39 & 30 & 9 & \multirow[t]{2}{*}{0.047} \\
\hline 3 & 22 & 11 & 11 & \\
\hline \multicolumn{5}{|l|}{ Tumor location } \\
\hline Left & 28 & 18 & 10 & \multirow[t]{3}{*}{0.489} \\
\hline Right & 26 & 13 & 13 & \\
\hline Both & 18 & 10 & 8 & \\
\hline \multicolumn{5}{|l|}{ Tumor size (cm) } \\
\hline$\leq 10$ & 29 & 17 & 12 & \multirow[t]{2}{*}{1.000} \\
\hline$>10$ & 32 & 19 & 13 & \\
\hline
\end{tabular}

IGF2, insulin-like growth factor 2 .

Biotechnology) as previously described (22). Tumor cell staining was evaluated and considered positive when immunoreactivity was $\geq 10 \%$. Positive staining was quantified and classified into 5 categories: $<10 \%$ positive cells as $0 ; 10$ to $25 \%$ as $1 ; 26$ to $50 \%$ as $2 ; 51$ to $75 \%$ as 3 and $\geq 76 \%$ as 4 . Staining intensity was graded as negative $(0)$, weak (1), moderate (2) or strong (3). All core biopsies were independently reviewed by two pathologists, and the expression level was defined by the sum of positive staining and intensity.

Statistical analysis. Statistical analyses were performed using SPSS 13.0 software (SPSS, Inc., Chicago, IL, USA). Results are expressed as the mean \pm standard deviation (SD). Measurement data were analyzed by a Student's t-test, and the Chi-square test was used to analyze the differences between categorical variables. A Kaplan-Meier survival database that contained the survival information of ovarian cancer patients and gene expression data obtained by using Affymetrix microarrays was used (23). The probe set was 202409_at (there are 3 IGF2 probe sets: 210881_s_at, 202410_x_at and 202409_at). Although the probe sets are different, the result was similar. The patients were grouped according to the median or auto selection of the best cut-off value. $\mathrm{P}<0.05$ was considered to be statistically significant.

\section{Results}

IGF2 is frequently increased in human ovarian cancer tissues. To investigate the level of IGF2 expression in 

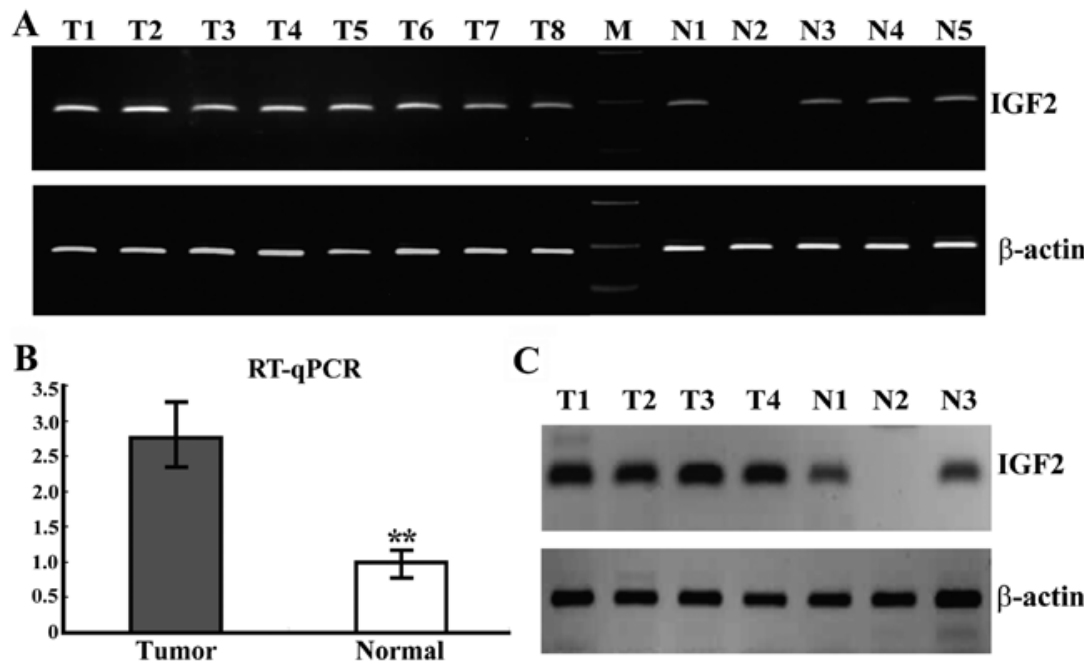

C

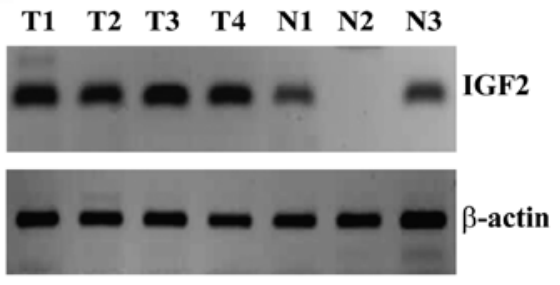

Figure 1. IGF2 expression is frequently increased in human ovarian cancer tissues. (A) RT-PCR analysis of IGF2 mRNA levels in the normal and cancerous ovarian tissues. T, ovarian tumor tissues; $\mathrm{M}$, marker; $\mathrm{N}$, normal ovarian tissues. $\beta$-actin was used as an internal control. (B) The IGF2 mRNA levels were detected by RT-qPCR analysis in the normal ovarian and ovarian tumor tissues. The different normal ovarian and ovarian tumor tissues were mixed together from 5 and 10 individual patients, respectively. $\beta$-actin was used as an internal control. ${ }^{* *} \mathrm{P}<0.01$. Error bars indicate SD (n=3). (C) IGF2 protein levels were detected by WB in normal ovarian and ovarian tumor tissues. $\beta$-actin was used as an internal control. IGF2, insulin-like growth factor 2 ; WB, western blotting.
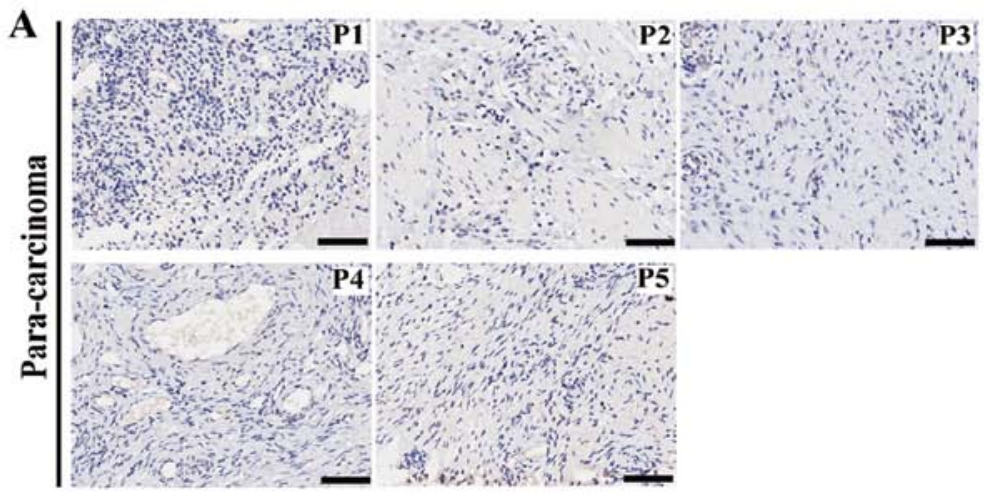

C

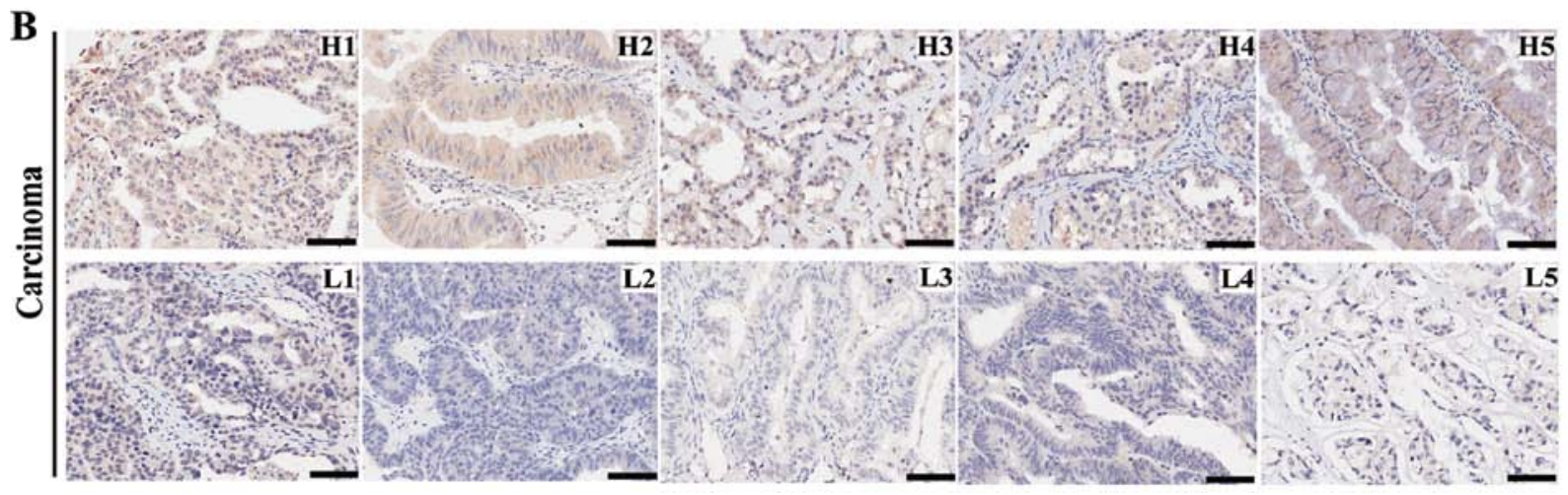

Figure 2. IGF2 expression is higher in carcinoma tissues than that in para-carcinoma tissues. (A) Immunohistochemical analysis of IGF2 expression was performed in the corresponding non-cancerous samples. Low levels of IGF2 expression were observed in most corresponding non-cancerous tissues compared to the levels in the cancerous tissues. Scale bars, $50 \mu \mathrm{m}$. The results are shown in representative samples. (B) High and low expression levels of IGF2 are shown in representative tumor ovarian tissues. $\mathrm{H}$, high expression of IGF2; L, low expression of IGF2. Scale bars, $50 \mu \mathrm{m}$. (C) The expression level of IGF2 was quantified. The mean expression of IGF2 was higher in the cancer tissues than that in the para-carcinoma tissues, ${ }^{* *} \mathrm{P}<0.01$. Error bars indicate $\mathrm{SD}(\mathrm{n}=3)$. IGF2, insulin-like growth factor 2.

human ovarian cancers, RT-PCR and RT-qPCR assays were performed in 10 normal ovarian (10 different normal ovaries) and 35 ovarian cancer tissues ( 35 different ovarian cancers). The expression of IGF2 in most cases (30/35) of tumor tissues was upregulated compared to the mean expression of the 10 normal ovarian tissues, and the mean expression of IGF2 in cancer tissues $(2.86 \pm 0.72)$ was markedly higher than that in the normal ovarian tissues $(1.00 \pm 0.18)(\mathrm{P}=0.000$, Fig. 1A and B). The data showed that IGF2 was frequently increased in the tumor tissues compared to the frequency in 

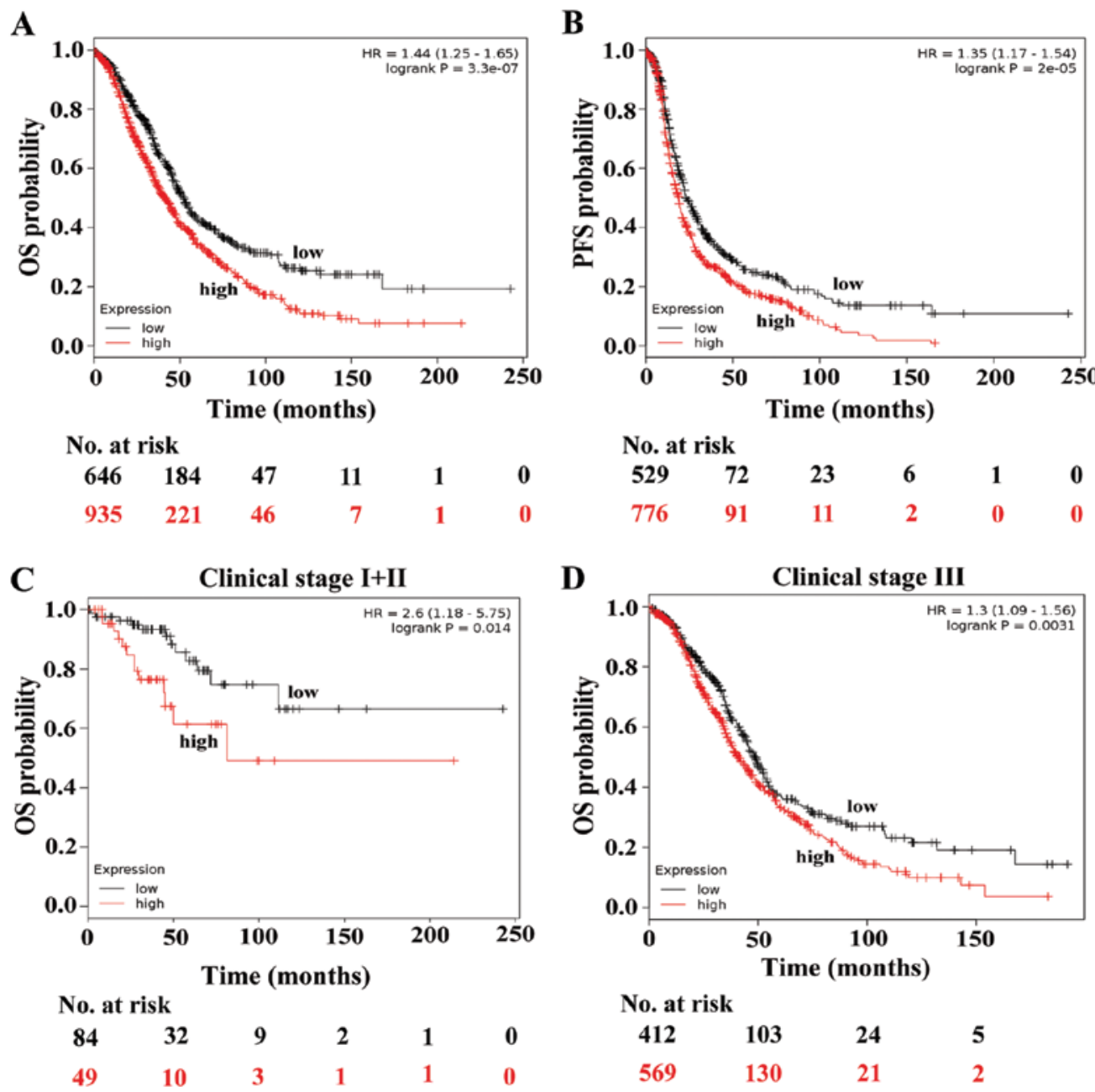

Figure 3. High expression of IGF2 is correlated with reduced survival in ovarian cancer patients. (A) Kaplan-Meier survival analysis of IGF2 expression and overall survival (OS) in 1,581 ovarian cancer patients with Kaplan-Meier plotter (http: //kmplot.com/analysis/index). The OS was reduced in the IGF2 high expression group when compared with that in the IGF2 low expression group. Auto select best cut-off was chosen in the analysis; the cut-off value used was 729; expression range of the probe was 3-66,014. (B) Kaplan-Meier survival analysis between IGF2 expression and progression-free survival (PFS) in 1,305 ovarian cancer patients with Kaplan-Meier plotter. The PFS was reduced in the IGF2 high expression group when compared with that in the IGF2 low expression group. Auto select best cut-off was chosen in the analysis; the cutoff value used was 671; expression range of the probe was 3-66,014. (C) KaplanMeier survival analysis of IGF2 expression in 133 patients at stage I+II in the ovarian cancers. Auto select best cut-off was chosen in the analysis; the cut-off value used was 1,273; Expression range of the probe was 4-46,435. (D) Kaplan-Meier survival analysis of IGF2 expression in 981 patients at stage III in the ovarian cancers. Auto select best cut-off was chosen in the analysis; the cut-off value used was 729; expression range of the probe was 5-53,779. IGF2, insulinlike growth factor 2 .

the normal ones, which was further confirmed by WB at the protein level (Fig. 1C).

IGF2 expression is correlated with histological grade of ovarian cancer patients. To confirm whether the IGF2 protein level is altered in cancer, we also conducted IHC for IGF2 on a TMA containing 72 cancer and 15 para-carcinoma ovarian tissues. The IGF2 protein level was increased in most (61/72) cancer tissues compared to the level in the para-carcinoma ovarian tissues, and the mean expression of IGF2 in cancer tissues $(2.25 \pm 0.37)$ was evidently higher than that in the paracarcinoma ovarian tissues $(0.90 \pm 0.12)(\mathrm{P}=0.000$, Fig. $2 \mathrm{~A}-\mathrm{C})$. After investigating the associations between IGF2 expression and clinicopathologic features of the ovarian cancer patients, IGF2 expression was found to be significantly correlated with histological grade $(\mathrm{P}=0.047)$. However, IGF2 expression was not correlated with age, histological type, tumor size or location (Table I).

High expression of IGF2 is significantly associated with poor overall survival (OS) of ovarian cancer patients. To investigate the correlation between IGF2 expression and survival of the tumor patients, we examined the contribution of IGF2 expression to the OS of the ovarian cancer patients in a clinical microarray database (23). This database collected gene expression data obtained by using Affymetrix microarrays and the OS information of 1,648 ovarian cancer patients. The OS analysis revealed that high expression of IGF2 predicts poorer survival of ovarian cancer patients $(\mathrm{HR}=1.44, \mathrm{P}=0.000$, Fig. 3A). In addition, the patients with high IGF2 expression also had a poorer progression-free survival (PFS) compared with the low expression group ( $\mathrm{HR}=1.35, \mathrm{P}=0.000$, Fig. $3 \mathrm{~B})$. 
A
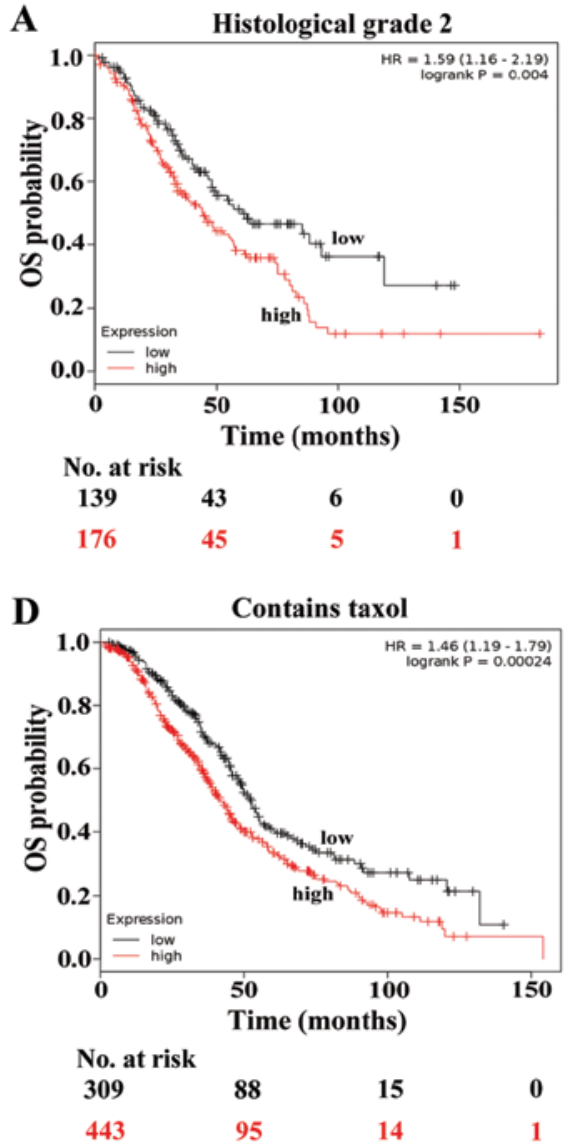

B

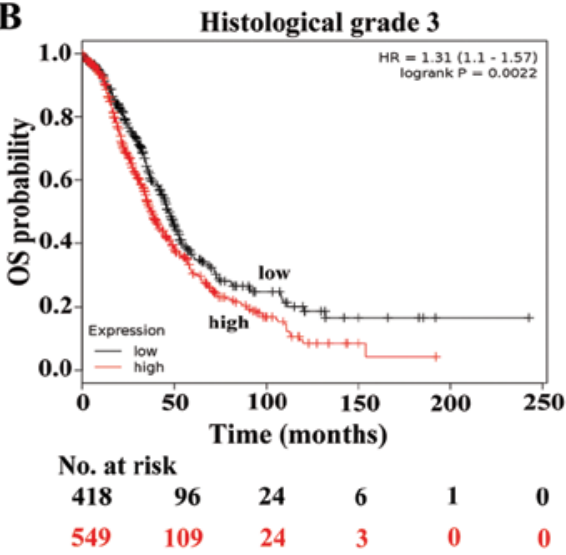

E

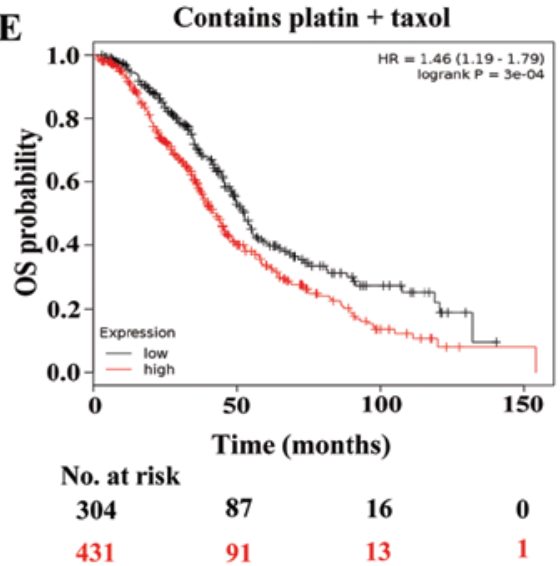

C

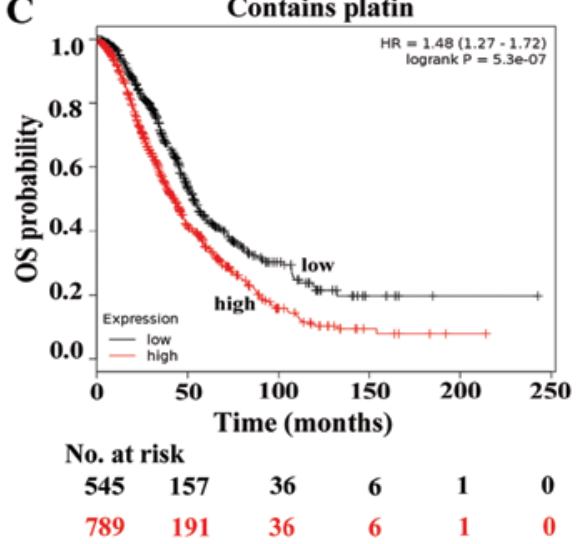

Figure 4. High expression of IGF2 is correlated with poorer OS in ovarian cancer patients. (A) Survival analysis of IGF2 expression in 315 patients at grade 2 in the ovarian cancers. Auto select best cut-off was chosen in the analysis; the cut-off value used was 1,041; expression range of the probe was $9-43,306$. (B) Survival analysis of IGF2 expression in 967 patients at grade 3 in the ovarian cancers. Auto select best cut-off was chosen in the analysis; the cut-off value used was 729; expression range of the probe was 3-53,779. (C) Kaplan-Meier survival analysis of IGF2 expression in 1,334 patients treated with chemotherapy containing platin in the ovarian cancers. Auto select best cut-off was chosen in the analysis; the cut-off value used was 739 ; expression range of the probe was 3-66,014. (D) Kaplan-Meier survival analysis of IGF2 expression in 752 patients treated with chemotherapy containing Taxol in the ovarian cancers. Auto select best cut-off was chosen in the analysis; the cut-off value used was 729; expression range of the probe was 4-53,779. (E) Survival analysis of IGF2 expression in 735 patients treated with chemotherapy containing platin and Taxol in the ovarian cancers. Auto select best cut-off was chosen in the analysis; the cut-off value used was 739; expression range of the probe was 4-53,779. IGF2, insulin-like growth factor 2; OS, overall survival.

High expression of IGF2 predicts poorer survival of the patients at clinical stage I+II and III. To determine the association between IGF2 expression and the OS of ovarian patients with different stages, we analyzed the survival data of patients with different stages stratifying the patients based on IGF2 expression. IGF2 expression was not associated with OS time of ovarian patients at stage IV $(\mathrm{P}=0.301)$. However, there was a statistically significant effect of high IGF2 expression on the poorer OS of the ovarian cancer patients at stage I+II $(\mathrm{HR}=2.60, \mathrm{P}=0.014)$ and III $(\mathrm{HR}=1.30, \mathrm{P}=0.003$, Fig. $3 \mathrm{C}$ and D). These findings suggest that high expression of IGF2 is an unfavorable factor for the prognosis of ovarian cancers at stage I+II and III.

High expression of IGF 2 predicts poorer outcomes of the patients at grade 2 and 3. We then analyzed the survival data of patients at different grades by stratifying the patients based on IGF2 expression. We observed a statistically significant effect of high IGF2 expression on the poorer OS of the ovarian cancer patients at grade $2(\mathrm{HR}=1.59, \mathrm{P}=0.004)$ and $3(\mathrm{HR}=1.31$,
$\mathrm{P}=0.002$, Fig. $4 \mathrm{~A}$ and $\mathrm{B}$ ), but no effect on that of the patients at grade $1(\mathrm{P}=0.289)$. The results suggest that high expression of IGF2 is an unfavorable factor for the prognosis of ovarian cancers at grade 2 and 3 .

High expression of IGF2 implies poorer outcomes of the patients treated with chemotherapy containing platin and taxol. We next aimed to ascertain whether high expression of IGF2 also predicts poorer survival of the ovarian cancer patients treated with different chemotherapeutic agents. We found a statistically significant effect of high IGF2 expression on the poorer OS of the ovarian cancer patients treated with chemotherapy containing platin $(\mathrm{HR}=1.48, \mathrm{P}=0.000)$ and chemotherapy containing taxol $(\mathrm{HR}=1.46, \mathrm{P}=0.00024$, Fig. 4C and D). To further validate the results, we analyzed the association between IGF2 expression and OS times of the ovarian patients treated with chemotherapy containing platin and taxol. There was also a statistically significant effect of high IGF2 expression on the poorer OS of the patients treated with chemotherapy containing platin and taxol $(\mathrm{HR}=1.46$, 
$\mathrm{P}=0.000$, Fig. 4E). However, no effect of high IGF2 expression was observed on the OS of the patients treated with chemotherapy containing avastin, docetaxel, gemcitabine, paclitaxel or topotecan.

\section{Discussion}

Accumulating data reveal the activation of IGF2 in subsets of embryonic tumors, such as hepatoblastoma, neuroblastoma, Wilms tumors and rhabdomyosarcoma $(24,25)$. Dysregulation of IGF2 was also found in subsets of adult cancers, and overexpression of IGF2 was detected in many tumors, for example, in $\sim 40 \%$ of colon carcinoma, $20 \%$ of hepatocarcinoma, $90 \%$ of liposarcoma and adrenocortical carcinoma (10,26-28). In the present study, we found that IGF2 expression was increased in $\sim 85.7 \%$ (30/35) of the ovarian cancer cases at the mRNA level and $84.7 \%(61 / 72)$ at the protein level, and the mean expression of IGF2 in the tumor tissues was obviously higher compared to that in the non-tumor ovarian tissues $(\mathrm{P}=0.000)$.

Previous studies have shown that IGF2 mutations are associated with risk for oral, colon and hepatocellular carcinoma (29-31). Extensive evidence indicates that increased IGF2 expression in tumors is associated with poorer prognosis, for instance more rapid disease progression in chronic myeloid leukemia, shorter time to disease recurrence in esophageal cancer and higher mortality in breast cancer $(17,18,32)$. Moreover, transgenic mice overexpressing IGF2 have a high risk of developing mammary gland adenocarcinoma and lung cancer, while the animals with low IGF2 expression usually live longer, and have a lower incidence of tumors (33-37). In the present study, we found that the ovarian cancer patients with high IGF2 expression had poorer OS and PFS compared with the low expression group, suggesting that the expression of IGF2 could act as a potential biomarker for prognostic evaluation of ovarian cancers.

To further determine the association between IGF2 expression and OS of ovarian cancer patients with different clinical stages, histological grades and chemotherapeutic treatments, survival data were analyzed by stratifying the patients based on the IGF2 levels. The results showed that high expression of IGF2 may be an unfavorable factor for the prognosis of ovarian cancer patients who were at clinical stage I+II and III, histological grade 2 and 3 or treated with chemotherapy containing platin and Taxol.

At present, the standard treatment for ovarian cancer is surgery and systemic chemotherapy, usually with the combination of taxol and platinum $(6,7)$. Unfortunately, the majority of these patients still succumb to recurrent, progressive disease due to resistance to chemotherapy. A recent study has shown that the silencing of IGF2 can restore taxol sensitivity in drugresistant ovarian cancer $(38,39)$. This study is consistent with our result that high expression of IGF2 may be an unfavorable factor for the prognosis of ovarian cancer patients.

Taken together, the present study revealed that IGF2 is upregulated in ovarian cancer tissues, and its expression may be a potential marker for prognostic evaluation of ovarian cancers. However, further investigation of the potential of IGF2 as a therapeutic target is clearly warranted in ovarian cancer.

\section{Acknowledgements}

This study was supported by the National Natural Science Foundation of China (no. 81172714).

\section{References}

1. Jemal A, Bray F, Center MM, Ferlay J, Ward E and Forman D: Global cancer statistics. CA Cancer J Clin 61: 69-90, 2011.

2. Siegel R, Naishadham D and Jemal A: Cancer statistics, 2013. CA Cancer J Clin 63: 11-30, 2013.

3. Chen YL, Cheng WF, Chang MC, Lin HW, Huang CT, Chien CL and Chen CA: Interferon-gamma in ascites could be a predictive biomarker of outcome in ovarian carcinoma. Gynecol Oncol 131: 63-68, 2013.

4. White KL,Schildkraut JM,Palmieri RT,Iversen ES Jr, BerchuckA, Vierkant RA, Rider DN, Charbonneau B, Cicek MS, Sutphen R, et al; Ovarian Cancer Association Consortium: Ovarian cancer risk associated with inherited inflammation-related variants. Cancer Res 72: 1064-1069, 2012.

5. Koyanagi T, Suzuki Y, Saga Y, Machida S, Takei Y, Fujiwara H, Suzuki $M$ and Sato Y: In vivo delivery of siRNA targeting vasohibin-2 decreases tumor angiogenesis and suppresses tumor growth in ovarian cancer. Cancer Sci 104: 1705-1710, 2013.

6. Vaughan S, Coward JI, Bast RC Jr, Berchuck A, Berek JS, Brenton JD, Coukos G, Crum CC,Drapkin R, Etemadmoghadam D, et al: Rethinking ovarian cancer: Recommendations for improving outcomes. Nat Rev Cancer 11: 719-725, 2011.

7. Tsofack SP, Meunier L, Sanchez L, Madore J, Provencher D, Mes-Masson AM and Lebel M: Low expression of the X-linked ribosomal protein S4 in human serous epithelial ovarian cancer is associated with a poor prognosis. BMC Cancer 13: 303, 2013.

8. Marsh S: Pharmacogenomics of taxane/platinum therapy in ovarian cancer. Int J Gynecol Cancer 19 (Suppl 2): S30-S34, 2009.

9. Kartalou M and Essigmann JM: Mechanisms of resistance to cisplatin. Mutat Res 478: 23-43, 2001.

10. Livingstone C: IGF2 and cancer. Endocr Relat Cancer 20: R321-R339, 2013.

11. Yu H, Mistry J, Nicar MJ, Khosravi MJ, Diamandis A, van Doorn J and Juul A: Insulin-like growth factors (IGF-I, free IGF-I and IGF-II) and insulin-like growth factor binding proteins (IGFBP-2, IGFBP-3, IGFBP-6, and ALS) in blood circulation. J Clin Lab Anal 13: 166-172, 1999.

12. Raynaud-Simon A: Levels of plasma insulin-like growth factor I (IGF I), IGF II, IGF binding proteins, type $1 \mathrm{IGF}$ receptor and growth hormone binding protein in community-dwelling elderly subjects with no malnutrition and no inflammation. J Nutr Health Aging 7: 267-273, 2003.

13. O'Dell SD and Day IN: Insulin-like growth factor II (IGF-II). Int J Biochem Cell Biol 30: 767-771, 1998.

14. Liu L, Greenberg S, Russell SM and Nicoll CS: Effects of insulin-like growth factors I and II on growth and differentiation of transplanted rat embryos and fetal tissues. Endocrinology 124: 3077-3082, 1989

15. Yu H and Rohan T: Role of the insulin-like growth factor family in cancer development and progression. J Natl Cancer Inst 92: 1472-1489, 2000.

16. El Tayebi HM, Salah W, El Sayed IH, Salam EM, Zekri AR, Zayed N, Salem ES, Esmat G and Abdelaziz AI: Expression of insulin-like growth factor-II, matrix metalloproteinases, and their tissue inhibitors as predictive markers in the peripheral blood of HCC patients. Biomarkers 16: 346-354, 2011.

17. Zhao R, DeCoteau JF, Geyer CR, Gao M, Cui H and Casson AG: Loss of imprinting of the insulin-like growth factor II (IGF2) gene in esophageal normal and adenocarcinoma tissues. Carcinogenesis 30: 2117-2122, 2009.

18. Kalla Singh S, Tan QW, Brito C, De León M, Garberoglio C and De León D: Differential insulin-like growth factor II (IGF-II) expression: A potential role for breast cancer survival disparity. Growth Horm IGF Res 20: 162-170, 2010.

19. Deng J, Dong Y, Li C, Zuo W, Meng G, Xu C and Li J: Decreased expression of C10orf 10 and its prognostic significance in human breast cancer. PLoS One 9: e99730, 2014.

20. Gao Q, Qiu SJ, Fan J, Zhou J, Wang XY, Xiao YS, Xu Y, Li YW and Tang ZY: Intratumoral balance of regulatory and cytotoxic $\mathrm{T}$ cells is associated with prognosis of hepatocellular carcinoma after resection. J Clin Oncol 25: 2586-2593, 2007. 
21. Han F, Liu W, Jiang X, Shi X, Yin L, Ao L, Cui Z, Li Y, Huang C, Cao J, et al: SOX30, a novel epigenetic silenced tumor suppressor promotes tumor cell apoptosis by transcriptional activating p53 in lung cancer. Oncogene: Dec 1, 2014 (Epub ahead of print). doi: 10.1038/onc.2014.370.

22. Han F, Dong Y, Liu W, Ma X, Shi R, Chen H, Cui Z, Ao L, Zhang H, Cao J, et al: Epigenetic regulation of sox 30 is associated with testis development in mice. PLoS One 9: e97203, 2014.

23. Gyorffy B, Lánczky A and Szállási Z: Implementing an online tool for genome-wide validation of survival-associated biomarkers in ovarian-cancer using microarray data from 1287 patients. Endocr Relat Cancer 19: 197-208, 2012.

24. El-Badry OM, Romanus JA, Helman LJ, Cooper MJ, Rechler MM and Israel MA: Autonomous growth of a human neuroblastoma cell line is mediated by insulin-like growth factor II. J Clin Invest 84: 829-839, 1989.

25. Zhan S, Shapiro DN and Helman LJ: Activation of an imprinted allele of the insulin-like growth factor II gene implicated in rhabdomyosarcoma. J Clin Invest 94: 445-448, 1994.

26. Tricoli JV, Rall LB, Karakousis CP, Herrera L, Petrelli NJ, Bell GI and Shows TB: Enhanced levels of insulin-like growth factor messenger RNA in human colon carcinomas and liposarcomas. Cancer Res 46: 6169-6173, 1986.

27. Cariani E, Lasserre C, Seurin D, Hamelin B, Kemeny F, Franco D Czech MP, Ullrich A and Brechot C: Differential expression of insulin-like growth factor II mRNA in human primary liver cancers, benign liver tumors, and liver cirrhosis. Cancer Res 48 6844-6849, 1988

28. Gicquel C, Bertagna X, Schneid H, Francillard-Leblond M Luton JP, Girard F and Le Bouc Y: Rearrangements at the 11p15 locus and overexpression of insulin-like growth factor-II gene in sporadic adrenocortical tumors. J Clin Endocrinol Metab 78 1444-1453, 1994

29. Yoon AJ, Zavras AI, Chen MK, Lin CW and Yang SF: Association between Gly1619ARG polymorphism of IGF2R domain 11 (rs629849) and advanced stage of oral cancer. Med Oncol 29: 682-685, 2012

30. Hoyo C, Murphy SK, Schildkraut JM, Vidal AC, Skaar D, Millikan RC, Galanko J, Sandler RS, Jirtle R and Keku T: IGF2R genetic variants, circulating IGF2 concentrations and colon cancer risk in African Americans and Whites. Dis Markers 32: 133-141, 2012.
31. Couvert P, Carrié A, Tezenas du Montcel S, Vaysse J, Sutton A, Barget N, Trinchet JC, Beaugrand M, Ganne N, Giral P, et al: Insulin-like growth factor 2 gene methylation in peripheral blood mononuclear cells of patients with hepatitis $\mathrm{C}$ related cirrhosis or hepatocellular carcinoma. Clin Res Hepatol Gastroenterol 36: 345-351, 2012.

32. Randhawa GS, Cui H, Barletta JA, Strichman-Almashanu LZ, Talpaz M, Kantarjian H, Deisseroth AB, Champlin RC and Feinberg AP: Loss of imprinting in disease progression in chronic myelogenous leukemia. Blood 91: 3144-3147, 1998.

33. Bates P, Fisher R, Ward A, Richardson L, Hill DJ and Graham CF: Mammary cancer in transgenic mice expressing insulin-like growth factor II (IGF-II). Br J Cancer 72: 1189-1193, 1995.

34. Moorehead RA, Sanchez OH, Baldwin RM and Khokha R: Transgenic overexpression of IGF-II induces spontaneous lung tumors: A model for human lung adenocarcinoma. Oncogene 22: 853-857, 2003.

35. Rogler CE, Yang D, Rossetti L, Donohoe J, Alt E, Chang CJ, Rosenfeld R, Neely K and Hintz R: Altered body composition and increased frequency of diverse malignancies in insulin-like growth factor-II transgenic mice. J Biol Chem 269: 13779-13784, 1994.

36. Pravtcheva DD and Wise TL: Metastasizing mammary carcinomas in $\mathrm{H} 19$ enhancers-Igf 2 transgenic mice. J Exp Zool 281: 43-57, 1998.

37. Bartke A, Chandrashekar V, Bailey B, Zaczek D and Turyn D: Consequences of growth hormone $(\mathrm{GH})$ overexpression and $\mathrm{GH}$ resistance. Neuropeptides 36: 201-208, 2002.

38. Huang GS, Brouwer-Visser J, Ramirez MJ, Kim CH, Hebert TM, Lin J, Arias-Pulido H, Qualls CR, Prossnitz ER, Goldberg GL, et al: Insulin-like growth factor 2 expression modulates Taxol resistance and is a candidate biomarker for reduced diseasefree survival in ovarian cancer. Clin Cancer Res 16: 2999-3010, 2010.

39. Brouwer-Visser J, Lee J, McCullagh K, Cossio MJ, Wang Y and Huang GS: Insulin-like growth factor 2 silencing restores taxol sensitivity in drug resistant ovarian cancer. PLoS One 9: e100165, 2014 